\title{
KAJIAN VARIABILITAS GALUR-GALUR PADI GOGO PADA LAHAN KERING MASAM
}

\author{
Angelita Puji Lestari ${ }^{1 *}$, Rini Hermanasari ${ }^{1}$, Yullianida ${ }^{1}$, Aris Hairmansis ${ }^{1}$ \\ ${ }^{1}$ Balai Besar Penelitian Tanaman Padi, Jl Raya 12 Sukamandi Subang 41256 \\ *Corresponding Author: ap_lestari@yahoo.com
}

\begin{abstract}
[VARIABILITY STUDIES OF UPLAND RICE LINES ON AN ACIDIC SOIL]. Suscessful upland rice breeding program to produce productive and adaptive to acid soil is dependent upon the extent of genetic variability of the breeding materials. Objectives of this study were to estimate the genetic variability, phenotypic and genotypic coeficient of variations, heritability, genetic advance, and correlation of five traits observed from dari 298 upland rice lines and five checks varieties.. A field field experiment arranged in an augmented design was conducted at the Tamanbogo Experimental Station in Lampung 1 MT 2019.. The results of the analysis of variance showed that there was diversity among lines, resulting in differences in appearance on plant height, number of productive tillers, and yields. High heritability, genetic advancement, and high correlation on the number of productive tiller indicate that this character is a selection criteria so that selection can be done in an effort to improve these characters.
\end{abstract}

Keyword: observation, yield of upland rice, acidic soil

\begin{abstract}
ABSTRAK
Keberhasilan program pemuliaan padi untuk menghasilkan varietas-varietas yang produktif dan adaptif pada lahan kering masam sangat bergantung pada besarnya keragaman genetik yang digunakan sebagai populasi dasar. Tujuan penelitian adalah untuk menaksir keragaman genetik, koefisien variasi genotipe dan fenotipe, heritabilitas, dan kemajuan genetik lima karakter yang diukur dari 298 galur padi gogo dan lima varietas pembanding. Penelitian lapangan dilaksanakan dengan rancangan bersekat di Percobaan Tamanbogo Lampung pada MT 12019 . Hasil analisis ragam menunjukkan keragaman nyata antar galur pada tinggi tanaman, jumlah anakan produktif, dan hasil. Namun demikian, hanya tinggi tanaman dan jumlah anakan produktif yang memiliki heritabilitas kemajuan genetik yang tinggi. Hasil analisis korelasi menunjukkan bahwa kedua karakter berkorelasi rendah dengan hasil, sehingga kriteria seleksi untuk peningkatan hasil hanya dapat didasarkan pada daya hasil galur.
\end{abstract}

Kata kunci: heritabilitas, kemajuan genetik, korelasi, lahan kering masam, padi gogo 


\section{PENDAHULUAN}

Lahan kering memiliki potensi yang besar untuk mendukung program peningkatan produksi beras nasional melalui peningkatan areal tanam. Pada tahun 2019 total luas panen padi di Indonesia mencapai 10,68 juta hektar, dan 1,16 juta ha di antaranya merupakan sumbangan dari lahan kering (BPS, 2020). Namun produktivitas padi di lahan kering secara nasional adalah 3.3 ton/ha, jauh di bawah rata-rata produktivitas padi sawah yang besarnya 5,3 ton /ha (Kementan, 2014).

Pertanaman padi gogo di Indonesia dapat dijumpai pada lahan kering dari dataran rendah sampai dataran tinggi (di atas $700 \mathrm{mdpl}$ ). Potensi lahan kering dataran rendah untuk pengembangan tanaman pangan, termasuk padi, mencapai 23,26 juta ha, sementara di dataran tinggi mencapai sekitar 2,07 juta ha (Abdulrachman et al., 2008).

Selain sebagai tanaman utama dengan pola monokultur, budidaya padi di lahan kering bisa dilakukan secara tumpang sari dengan tanaman perkebunan dan hutan tanaman industri (Toha et al., 2009). Padi dapat ditanam di sela-sela tanaman perkebunan seperti kelapa sawit, kelapa dalam, karet, dan coklat, dan hutan tanaman industri seperti jati, akasia dan meranti. Selain itu padi gogo juga potensial untuk ditanam di selasela tanaman hortikultura tahunan seperti pohon jeruk, durian dan yang lainnya. Toha et al. (2009) mengestimasi luas lahan perkebunan dan HTI yang potensial untuk pengembangan padi gogo mencapai 2 juta ha/tahun.

Program pemuliaan padi gogo diarahkan untuk merakit varietas padi gogo yang berpotensi hasil tinggi, toleran terhadap cekaman biotik dan abiotik tertentu, serta bermutu beras baik. Sejumlah varietas unggul padi gogo telah dilepas oleh Badan Litbang Pertanian (Hairmansis et al., 2016). Varietas-varietas unggul seperti Inpago 8, Inpago 9 dan Inpago 12 selain tahan blas dan adaptif di lahan masam juga memiliki potensi hasil yang relatif tinggi mencapai 8-10 ton/ ha. Beberapa varietas juga telah berkembang luas di petani seperti Situ Patenggang dan Batutegi. Varietasvarietas tersebut diarahkan untuk budidaya padi di lahan kering dataran rendah sebagai tanaman monokultur. Sekalipun demikian, upaya pengembangan varietas padi gogo berdaya hasil tinggi dan adaptif pada lahanlahan kering bereaksi masam perlu terus dilakukan untuk memperbanyak pilihan petani dalam menentukan varietas yang paling sesuai di daerahnya. Tujuan dari penelitian ini adalah untuk menaksir keragaman dan parameter genetik yang dapat digunakan sebagai dasar dalam menentukan kriteria seleksi bagi galurgalur padi gogo yang selama ini telah dikembangkan untuk perakitan varietas-varietas padi gogo unggul yang adapatif pada lahan kering bereaksi masam.

\section{METODE PENELITIAN}

Percobaan lapangan dilaksanakan di Lampung pada pada MT 12019 dengan menggunakan rancangan bersekat (augmented design). Bahan yang digunakan pada percobaan ini adalah 298 galur padi gogo dari program pemuliaan BB Padi dan varietas pembanding. Setiap galur ditanam dengan ukuran plot $0.9 \mathrm{~m} \times 5 \mathrm{~m}$ dengan jarak tanam $30 \mathrm{~cm} \times 15 \mathrm{~cm}$. Dosis pupuk yang digunakan adalah $300 \mathrm{~kg} / \mathrm{ha}$ NPK + $100 \mathrm{~kg} / \mathrm{ha}$ Urea. Penyiangan dilakukan dua kali yaitu pada saat menjelang pemupukan susulan I dan II. Pengamatan yang dilakukan meliputi: tinggi tanaman, umur berbunga, umur panen, jumlah anakan, hasil gabah kering giling.

\section{HASIL DAN PEMBAHASAN}

Sebaran penampilan genotipe yang dievaluasi yang meliputi tinggi tanaman, umur berbunga, jumlah anakan produktif, dan hasil (Gambar 1. Untuk karakter tinggi tanaman $86.67 \mathrm{~cm}$, beberapa nomor memiliki tinggi tanaman lebih dari $100 \mathrm{~cm}$. Tanaman tinggi menyebabkan tanaman rentan rebah dan seleksi umumnya diarahkan untuk menghasilkan tanaman yang memiliki postur yang tingginya kurang dari 90 $\mathrm{cm}$. Umur berbunga menunjukkan bahwa rata-rata umur berbunga di atas 90 hari setelah sebar dan beberapa nomor di atas 100 hari setelah sebar, namun secara umum genotipe yang dievaluasi termasuk berumur sedang. Jumlah anakan produktif ratarata sebanyak 10 anakan dan jumlah tersebut umum dijumpai pada padi gogo (Yuniarti, 2015; Syahril, 2017).

Blok berpengaruh nyata terhadap seluruh karakter, sedangkan perbedaan genotipe berpengaruh nyata terhadap tinggi tanaman, jumlah anakan produktif, dan hasil (Tabel 1). Pernbedaan nyata antara galur dan cek dijumpai pada jumlah anakan produktif dan hasil. Hal ini menunjukkan bahwa terdapat keragaman antar galur sehingga menghasilkan perbedaan penampilan pada karakter tinggi tanaman, jumlah anakan produktif, dan hasil.

Seleksi terhadap karakter kuantitatif dapat dilakukan berdasarkan pada nilai parameter genetik tanpa mengabaikan nilai tengah populasi yang bersangkutan. Perbaikan karakter tanaman melalui program pemuliaan tanaman membutuhkan informasi tentang keragaman genetik dan heritabilitas. Informasi tersebut menjadi modal awal sebagai acuan untuk melakukan seleksi (Lasmiana et al., 2017). 

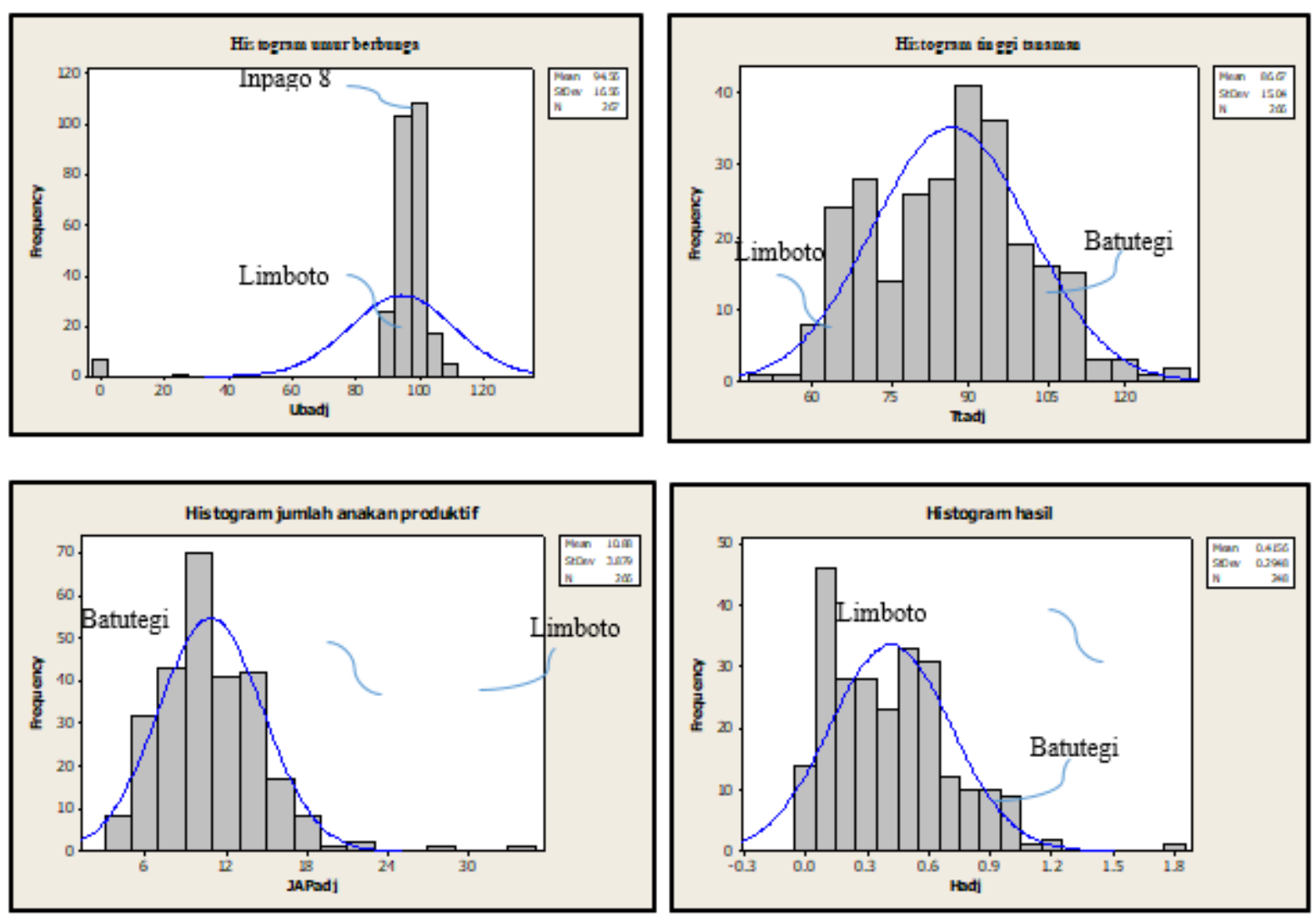

Gambar 1. Sebaran data karakter umur berbunga, tinggi tanaman, jumlah anakan produktif, dan hasil dari galur-galur yang diuji pada percobaan|observasi

Tabel 1. Kuadrat tengah dari lima karakter galur-galur padi yang diuji

\begin{tabular}{|c|c|c|c|c|c|}
\hline Sumber & Tinggi & J. Anakan & Umur & Umur & \multirow{2}{*}{ Hasil } \\
\hline keragaman & tanaman & produktif & berbunga & Panen & \\
\hline Blok & $4097^{*}$ & $1109^{*}$ & $360,8^{*}$ & $131,5^{*}$ & $3,04^{*}$ \\
\hline Genotipe & $613,8^{*}$ & $310,3^{*}$ & 46,3 & 11,4 & $0,29 *$ \\
\hline Galur vs cek & 0,004 & $241,7^{*}$ & 0,96 & 0,18 & $4,7^{*}$ \\
\hline Cek & $956,5^{*}$ & 25,6 & 48 & 19,9 & 0,05 \\
\hline Galat & $605,6^{*}$ & $321,9^{*}$ & 46,6 & 11,1 & $0,26^{*}$ \\
\hline $\mathrm{CV}$ & 15,4 & 26,4 & 5,4 & 3,18 & 19,1 \\
\hline
\end{tabular}

Data menunjukkan bahwa nilai heritabilitas tinggi pada tinggi tanaman dan jumlah anakan produktif (Tabel 2). Hal ini berarti kedua karakter tersebut sangat dipengaruhi oleh genetik dibandingkan faktor lingkungan. Oladosu et al. (2014) menyatakan nilai heritabilitas tinggi pada umur berbunga, umur panen, dan tinggi tanaman.
$\mathrm{KK}_{\mathrm{G}}, \mathrm{KK}_{\mathrm{F}}$, dan $\mathrm{K}_{\mathrm{G}}$ tinggi pada jumlah anakan produktif. Sedangkan hasil penelitian Pratap et al. (2012) menunjukkan bahwa nilai heritabilitas, KKG, KKF, dan kemajuan genetik tinggi terdapat pada jumlah anakan produktif dan hasil gabah. Sebagaimana dilaporkan Manjunatha et al 2017 dimana hasil memiliki nilai $\mathrm{KKG}$ tertinggi. 
Tabel 2. Parameter genetik karakter dari seluruh galur yang diuji

\begin{tabular}{|l|c|c|c|c|c|c|c|}
\hline & $\mathrm{V}_{\mathrm{G}}$ & $\mathrm{V}_{\mathrm{P}}$ & $\mathrm{h}^{2}$ & $\mathrm{KK}_{\mathrm{G}}$ & $\mathrm{KK}_{\mathrm{F}}$ & $\mathrm{KG}$ & $\mathrm{KG}(\%)$ \\
\hline Hasil & 0,05 & 3,25 & 0,02 & 54,2 & 433,8 & 0,06 & 13,9 \\
\hline Tinggi tanaman & 88,01 & 91,21 & 0,96 & 10,8 & 11 & 18,98 & 21,9 \\
\hline Jumlah anakan produktif & 59,12 & 62,32 & 0,95 & 70,6 & 72,5 & 15,43 & 141,8 \\
\hline Umur berbunga & 3,73 & 6,93 & 0,54 & 2 & 2,7 & 2,92 & 3,1 \\
\hline Umur panen & 0,78 & 3,98 & 0,2 & 0,7 & 1,6 & 0,81 & 0,7 \\
\hline
\end{tabular}

Keterangan : $\mathrm{VG}=$ ragam genotipe, $\mathrm{VP}=$ ragam fenotipe, $\mathrm{h} 2=$ heritabilitas, $\mathrm{KKG}=$ koefisien keragaman genetik

$\mathrm{KK}_{\mathrm{F}}=$ koefisien keragaman fenotipe, $\mathrm{KG}=$ kemajuan genetik

Widyayanti et al. (2017) menyampaikan hal berbeda yaitu nilai KKG tertinggi pada galur padi terdapat pada karakter tinggi tanaman dan nilai KKG paling rendah terdapat pada karakter umur berbunga dan umur panen. Tingginya nilai KKG menunjukkan peluang terhadap usaha-usaha perbaikan yang efektif melalui seleksi (Nur et al., 2012). Nilai KKF terlihat sedikit lebih tinggi dari KKG menunjukkan sedikitnya pengaruh lingkungan terhadap ekspresi galur (Sabesan et al., 2009) atau kontribusi genetik terhadap keragaman fenotipe lebih besar dibandingkan faktor lingkungan (Andriani \& Damanhuri, 2018). Data hasil korelasi menunjukkan bahwa karakter jumlah anakan produktif juga bekorelasi nyata positif terhadap hasil (Tabel 3).

Tabel 3. Korelasi antara karakter agronomi tanaman pada percobaan observasi

\begin{tabular}{l|c|c|c|c|c|}
\hline \multicolumn{1}{|c|}{ Karakter } & $\begin{array}{c}\text { Tinggi } \\
\text { tanaman }\end{array}$ & $\begin{array}{c}\text { Jumlah anakan } \\
\text { produktif }\end{array}$ & $\begin{array}{c}\text { Umur } \\
\text { berbunga }\end{array}$ & $\begin{array}{c}\text { Umur } \\
\text { panen }\end{array}$ & Hasil \\
\hline Tinggi tanaman & 1 & $-0,5 * *$ & $-0,5 * *$ & $-0,1$ & $-0,1$ \\
\hline $\begin{array}{l}\text { Jumlah anakan } \\
\text { produktif }\end{array}$ & & 1 & $0,8 * *$ & 0,1 & 0,2 \\
\hline $\begin{array}{l}\text { Umur berbunga } \\
\text { Umur panen }\end{array}$ & & & 1 & $0,6 * *$ & 0,05 \\
\hline
\end{tabular}

Heritabilitas tinggi bersama, kemajuan genetik, dan korelasi yang tinggi pada karakter jumlah anakan produktif menunjukkan bahwa karakter ini merupakan kriteria seleksi sehingga seleksi dapat dilakukan dalam upaya peningkatan karakter tersebut (Lingaiah et al., 2014).

Menurut Natawijaya (2012) tekanan seleksi dapat dilakukan pada karakter-karakter dengan keragaman genetik tinggi, selain itu karakter ini dapat digunakan sebagai kriteria seleksi. Dilaporkan juga oleh Nur et al. (2012) bahwa pada gandum karakter dengan nilai heritabilitas tinggi dan diikuti oleh keragaman genetik luas adalah jumlah anakan produktif, jumlah spikelet dan luas daun. Keragaman genetik yang luas dari suatu karakter mengindikasikan adanya peluang perbaikan karakter gandum melalui karakter tersebut sehingga untuk menentukan suatu karakter sebagai kriteria seleksi diperlukan nilai heritabilitas dan kemajuan genetik yang tinggi serta keragaman genetik yang luas.

\section{KESIMPULAN}

Secara umum, galur dan varietas pembanding yang dievaluasi memiliki keragaman yang tinggi pada tinggi tanaman, jumlah anakan produktif, dan hasil. Namun berdasarkan nilai heritabilitasnya dan kemajuan genetik yang dapat diharapkan, maka tinggi tanaman dan jumlah anakan produktif berpeluang besar untuk dapat diperbaiki, namun tidak demikian halnya dengan hasil yang memiliki heritabilitas dan kemajuan genetik rendah. Penggunaan tinggi tanaman, jumlah anakan produktif, umur berbunga,maupun umur panen sebagai kriteria seleksi untuk meningkatkan hasil tidak akan cukup efektif, karena tidak berkorelasi dengan hasil.

\section{DAFTAR PUSTAKA}

Abdulrachman, S., Suhartatik, E., Kasno, A. \& Setyorini, D. (2008). Modul Pemupukan Padi Sawah Spesifik Lokasi. Kerjasama Badan Penelitian dan Pengembangan Pertanian dan International Rice Research Institute.

Andriani, D. \& Damanhuri. (2018). Pola pewarisan toleransi kondisi anaerob padi (Oryza sativa L.). Jurnal Produksi Tanaman, 6(6), 12041210.

IRRI. (2014). Standard Evaluation System for Rice (SES). International Rice Research Institute, Philippines.

Lasmiana, Ganefianti, D.W. \& Alnopri. (2016). Ragam genetik dan heritabilitas peubah kualitatif dan peubah kuantitatif dua puluh genotipe 
cabai (Capsicum annuum L.). Akta Agrosia 19(1), 1-10. DOI: https://doi.org/10.31186/ aa. 19.1.1-10.

Lingaiah, N., Venkanna, V. \& Cheralu, C. (2014). Genetic variability analysis in rice (Oryza sativa L.). Int. J. Pure App. Biosci., 2(5), 203-204.

Manjunatha, B., Krishnappa, M. \& Kumara, B.N. (2017), Genetic variability studies in rice (Oryza sativa $\mathrm{L}$,) genotype. Trends in Biosciences, 10 (38), 8027-8028.

Natawijaya, A. (2012). Analisis genetik dan seleksi generasi awal segregan gandum (Triticum aestivum L,) berdaya hasil tinggi. Tesis. Sekolah Pascasarjana, Institut Pertanian Bogor, Bogor.

Nur, A., Trikoesoemaningtyas, Khumaida, N. \& Yahya, S. (2012). Evaluasi dan keragaman genetik 12 galur gandum introduksi di lingkungan tropika basah, Jurnal Agrivigor, 11(2), 230-243.

Oladosu, Y., Rafii, M.Y., Abdullah, N., Malek, M.A., Rahim, H.A., Hussin, G., Latif, M.A. \&_Kareem, I. (2014). . Genetic variability and selection criteria in rice mutant lines as revealed by quantitative traits. The Scientific World Journal, 2014, 1-12.

Pratap, N., Singh, P.K., Shekhar, R., Soni, S.K. \& Mall, A.K. (2012). Genetic variability, character association and diversity analyses for economic traits in rice (Oryza sativa L.). SAARC J. Agri., 10 (2), 83-94.
Sabesan, T., Suresh, R. \& Saravanan, K. (2009). Genetic variability and correlation for yield and grain quality characters of rice grown in coastal saline low land of Tamilnadu. Electronic Journal of Plant Breeding, 1, 56-59.

Syahril, M. (2017). Uji adaptasi beberapa kultivar padi gogo lokal Kabupaten Aceh timur di lahan kering kebun percobaan Universitas Samudra. Jurnal Penelitian Agrosamudra, 4(1), 71-76.

Toha, H. M., K. Pirngadi, K., Permadi,K. \& Fagi, A.M. (2009). Meningkatkan dan memantapkan produktivitas dan produksi padi gogo, In A,A, Daradjat, A, Setyono, A,K, Makarim, dan A, Hasanudin (Eds), Padi Inovasi Teknologi Produksi Buku 2. LIPI Press., Jakarta.

Widyayanti, S., Basunanda, P., Mitrowihardjo, S., Kristamtini. (2017). Keragaman genetik dan Heritabilitas karakter agronomi galur F4 padi beras hitam, Penelitian Pertanian Tanaman Pangan, 1(3), 191-199. DOI:http://dx.doi.org/10.21082/ jpptp.v1n3.2017.p191-199.

Yuniarti, S. (2015). Respons pertumbuhan dan hasil varietas unggul baru (VUB) padi gogo di Kabupaten Pandeglang, Banten. In Prosiding Seminar Nasional Masyarakat Biodiversity Indonesia (pp. 848-851). 